\title{
- O direito da pessoa com deficiência à informação em tempos da pandemia da Covid-19: uma questão de acessibilidade e inclusão
}

\author{
The right of people with disabilities to information in times of the \\ Covid-19 pandemic: a question of accessibility and inclusion
}

\begin{abstract}
Heloisa Helena Barbozaa (D)
Vitor Almeida ${ }^{b}$ * (1)

RESUMO: A internalização da Convenção Internacional dos Direitos da Pessoa com Deficiência com hierarquia de norma constitucional e a promulgação do Estatuto da Pessoa com Deficiência (Lei $n$. 13.146/2015) constituem o marco normativo brasileiro de proteção da pessoa com deficiência, cujo objetivo central encontra-se na promoção do exercício das liberdades e dos direitos fundamentais em igualdade de condições com as demais pessoas de modo a permitir a inclusão social e a cidadania. A adoção do modelo social da deficiência impõe o afastamento da visão puramente biomédica e exige uma compreensão pautada na interação entre os impedimentos físicos, sensoriais, mentais e intelectuais, de longa duração e as barreiras que são socialmente impostas e impedem a plena participação social. Nessa esteira, a informação é um direito fundamental da pessoa com deficiência que oportuniza o alcance dos demais direitos, assumindo perfil peculiar vinculado à acessibilidade que depende de informações claras, objetivas e em formato alcançável. O acesso à informação é imprescindível para a busca da superação das barreiras e a efetiva inclusão. Em tempos de pandemia da Covid-19, informações acessíveis e recomendações sobre higienização pessoal, formas de mitigação de infecções, planos de restrições públicas tornam-se ainda mais relevantes para a preservação da saúde e da própria vida das pessoas com deficiência. Por meio do método hipotético-dedutivo e de pesquisa bibliográfica e documental, o presente artigo tem por escopo analisar a efetividade do direito à informação acessível da pessoa com deficiência em razão da pandemia da Covid-19.
\end{abstract}

Palavras-chave: Direito à Informação; Acessibilidade; Pessoa com Deficiência; Pandemia; Barreiras; Covid19.

ABSTRACT: The internalization of the International Convention on the Rights of Persons with Disabilities with a constitutional rule hierarchy and the promulgation of the Statute of Persons with Disabilities (Law No. 13,146 / 2015) constitute the Brazilian legal framework for the protection of persons with disabilities, whose central objective it lies in promoting the exercise of fundamental freedoms and rights on equal terms with others in order to allow social inclusion and citizenship. The adoption of the social model of disability imposes a departure from the purely biomedical view and requires an understanding based on the interaction between physical, sensory, mental and intellectual impairments, of long duration and the barriers that are socially imposed and prevent full social participation. In this context, information is a fundamental right of the person with disabilities that makes it possible to reach other rights, assuming a peculiar profile linked to accessibility that depends on clear, objective information and in an accessible format. Access to information is essential for the search for overcoming barriers and effective inclusion. In times of Covid-19 pandemic, accessible information and recommendations on personal hygiene, ways of mitigating infections, public restraint plans become even more relevant for the preservation of the health and life of people with disabilities. Through the hypothetical-deductive method and bibliographic and documentary research, this article aims to analyze the effectiveness of the right to accessible information for people with disabilities due to the Covid-19 pandemic.

Keywords: Right to Information; Accessibility; Disabled Person; Pandemic; Barriers; Covid-19.

\footnotetext{
a Faculdade de Direito, Universidade do Estado do Rio de Janeiro, Rio de Janeiro, Brasil.

b Departamento de Direito, Humanidades e Letras, Universidade Federal Rural do Rio de Janeiro, Três Rios, Brasil.

*Correspondência para/Correspondence to: Vitor Almeida. E-mail: almeida.vitor@yahoo.com.br.
}

Recebido em/Received: 15/08/2020; Aprovado em/Approved: 09/11/2020.

Artigo publicado em acesso aberto sob licença CC BY 4.0 Internacional 


\section{NOTAS INTRODUTÓRIAS: DIREITO À INFORMAÇÃO, PESSOAS COM DEFICIÊNCIA E COVID-1}

A garantia constitucional da liberdade de expressão e de informação abrange direitos fundamentais essenciais a uma sociedade livre e democrática. A Declaração Universal dos Direitos do Homem ${ }^{1}$ e as Constituições democráticas asseguram a defesa das liberdades comunicativas e informativas, na dimensão coletiva, como valores constitutivos centrais e estruturantes da democracia e, por conseguinte, do próprio exercício da cidadania. Em perspectiva individual, a livre manifestação de pensamento é justificada "como manifestação e corolário da especial dignidade humana, centro espiritual e moral da produção de sentido e cultura" (BINENBOJM, 2020, p. 23). As liberdades de comunicar-se, expressar ideias, opiniões e crenças, e de informar-se e informar fatos e dados são constitutivos da vida gregária plural e permitem o próprio desenvolvimento da personalidade de cada indivíduo para fins de exercício da sua autonomia de forma consciente e livre.

A Constituição da República de 1988 garante a liberdade de manifestação do pensamento e da atividade intelectual, artística, científica e de comunicação, independentemente de censura ou licença (art. $5^{\circ}$, inciso IX). No mesmo texto constitucional, assegura-se o direito à informação livre "como um direito de toda a cidadania, abarcando as liberdades de informar, informar-se e ser informado" (BINENBOJM, 2020, p. 27).

O acesso à informação assegurado às pessoas com deficiência assume função própria no contexto do modelo social de deficiência, visto que se torna elemento essencial para que se eliminem as barreiras sociais que impedem o exercício da autonomia individual comprometendo o processo de inclusão social. O acesso à informação clara, objetiva e em formato acessível é fundamental para o alcance dos objetivos esculpidos na Convenção Internacional dos Direitos das Pessoas com Deficiência (CDPD) e na Lei Brasileira de Inclusão (LBI), na medida em que permite a atuação com competência, voz e efetiva liberdade para o exercício da capacidade civil e, em especial, comunicar suas ideias, opiniões e crenças.

Desde dezembro de 2019, a sociedade global tem se deparado com um cotidiano pandêmico de um vírus de baixa letalidade, mas com potencial de transmissão ainda desconhecido e sem tratamento ou cura cientificamente comprovados. O chamado novo coronavírus (SARS-CoV2) surgiu em Wuhan, China, no final de 2019, tendo se espalhado rapidamente para todas as províncias chinesas e já alcançou a maior parte dos países em todo o mundo. Em tempos de pandemia do novo coronavírus, observase que a crise transborda o contexto médico-sanitário e impacta, a um só tempo, o ambiente econômico, político e social, bem como provoca uma verdadeira ruptura em todo o tecido da sociedade a partir de um cotidiano que requer isolamento e novas práticas sociais.

Em 11 de março de 2020, a Organização Mundial de Saúde (OMS) classificou como pandemia a enfermidade provocada pelo citado vírus, designada Covid-19, que já vitimou mais de oitocentas mil pessoas no mundo - no Brasil, o número se aproxima de cento e trinta mil mortos - e continua a aumentar. Em 30 de janeiro, a OMS já havia declarado que o surto do novo coronavírus constitui uma Emergência de Saúde Pública de Importância Internacional (ESPII) - o mais alto nível de alerta da Organização,

\footnotetext{
1 DUDH, art. XIX: "Todo ser humano tem direito à liberdade de opinião e expressão; este direito inclui a liberdade de, sem interferência, ter opiniões e de procurar, receber e transmitir informações e ideias por quaisquer meios e independentemente de fronteiras".
} 
conforme previsto no Regulamento Sanitário Internacional. A Portaria MS n. 188, de 3 de fevereiro de 2020, declarou a Emergência em Saúde Pública de Importância Nacional (ESPIN) em decorrência da Infecção Humana pelo novo Coronavírus (2019nCoV), nos termos dispostos pelo Decreto n. 7.616/2011. Por sua vez, a Lei n. 13.979, de 6 de fevereiro de 2020, dispôs sobre as medidas de enfrentamento ao surto decorrente da Covid-19.

Diante de tal cenário, indiscutível o agravamento da vulnerabilidade de algumas pessoas ou grupos sociais em razão da pandemia que atinge a todos, mas seus efeitos são sentidos de forma diferenciada. Segundo Boaventura de Sousa Santos "qualquer quarentena é discriminatória, mais difícil para uns grupos sociais do que para outros e impossível para um vasto grupo de cuidadores, cuja missão é tornar possível a quarentena ao conjunto da população". Por isso, observa que alguns grupos "padecem de uma especial vulnerabilidade que precede a quarentena e se agrava com ela" (2020, n.p.). Esses grupos compõem o que o autor chama de Sul, que em sua concepção "designa um espaço-tempo político, social e cultural. É a metáfora do sofrimento humano injusto causado pela exploração capitalista, pela discriminação racial e pela discriminação sexual" (2020, n.p.). Desse modo, as pessoas com deficiência física, sensorial, mental e intelectual são especialmente atingidas pela pandemia, que agrava sua intrínseca vulnerabilidade e são mais severamente vítimas de discriminação.

Segundo a Organização Pan-Americana de Saúde (OPAS), pessoas com deficiência têm maiores possibilidades de serem infectadas pelo coronavírus por diversos motivos que se assentam desde as maiores dificuldades de obter informações de saúde pública até as barreiras na implementação das medidas básicas de higiene, dificuldades de manter o isolamento social pois precisam de cuidadores, bem como precisam, em diversas situações, tocar nos objetos para obter informações, barreiras para acessar o sistema de saúde, para acessar informações, além de a Covid-19 potencializar condições préexistentes (OPAS, 2020, p. 2). Por isso, inúmeras associações de defesa das pessoas com deficiência manifestaram preocupação com a elaboração de protocolos de alocação de recursos escassos que desconsideram a prioridade desse grupo. ${ }^{2}$

Diante desse contexto, fundamental assegurar por meio de políticas públicas adequadas e eficientes serviços de apoio, assistência pessoal e acessibilidade física e comunicacional em tempos de pandemia da Covid-19, de modo a permitir que as pessoas com deficiência sejam efetivamente incluídas e tenham um tratamento em condições de igualdade com as demais pessoas, sob pena de completo esvaziamento da CDPD e do EPD. A priorização dos cuidados e do apoio necessário às pessoas com deficiência no contexto da pandemia se impõe como medida para evitar atos discriminatórios e a segregação.

A rigor, tais questões que acentuam a vulnerabilidade da pessoa com deficiência no cenário da pandemia da Covid-19 encontram no direito à informação acessível a sua fonte central para o respeito e a inclusão por meio de medidas e políticas concretas de acessibilidade, de caráter fundamental no direito brasileiro. O fornecimento de informações em formatos acessíveis e diversificados visa atender às diferentes necessidades de formas de comunicação compreensíveis, o que se torna fundamental para a mitigação de infecções, planos públicos de restrição social e acesso aos serviços oferecidos.

\footnotetext{
${ }^{2}$ Como, por exemplo, a Aliança Internacional de Pessoas com Deficiência, a partir das principais barreiras enfrentadas pelas pessoas com deficiência no contexto da pandemia da Covid-19, compilou 10 recomendações (IDA, 2020).
} 
O problema central, portanto, a ser analisado no presente trabalho reside na análise do papel da informação no contexto do modelo social de deficiência, em especial da informação acessível e diversificada para pessoas com deficiência no momento da pandemia da Covid-19, como uma questão de inclusão e acessibilidade, indispensável para os cuidados da saúde e de preservação da vida, bem como o exercício da cidadania. Para tanto, por meio do método dedutivo, abordagem qualitativa e técnica de pesquisa bibliográfica e documental, a partir dos marcos normativos de proteção das pessoas com deficiência no direito brasileiro, o objetivo central consiste em delinear o perfil peculiar da informação no contexto da Lei Brasileira de Inclusão (LBI), como um dos pressupostos essenciais da inclusão, bem como apontar os principais desafios e barreiras impostos pela pandemia da Covid-19 no que diz respeito ao acesso à informação pelas pessoas com deficiência.

\section{A PESSOA COM DEFICIÊNCIA NO DIREITO BRASILEIRO}

O Estatuto da Pessoa com Deficiência (Lei n. 13.146/2015) foi fruto de uma longa e árdua conquista dos movimentos em prol do reconhecimento das pessoas com deficiência, já há bastante tempo articulados na sociedade civil internacional, com o intuito de tornar visível parcela da população imemorialmente estigmatizada e vulnerável. A lei nacional modificou profundamente institutos importantes da dogmática civilista, como o regime das (in)capacidades e a curatela, além de alterar outros dispositivos do Código Civil e leis infraconstitucionais. Seu precípuo objetivo de plena inclusão e garantia dos direitos fundamentais das pessoas com deficiência em igualdade de participação na sociedade com as demais pessoas é festejado na medida em que assegura e promove o respeito à inerente dignidade de todos os indivíduos e busca efetivar a igualdade substancial.

Elaborada na linha da Convenção Internacional das Pessoas com Deficiência, de 2007, a Lei Brasileira de Inclusão, como também é expressamente denominada, objetiva proporcionar uma vida independente às pessoas com deficiência, como indivíduos autônomos para decidir sobre seus próprios destinos, sobretudo no que respeita a questões no campo existencial. Mais uma vez, a experiência brasileira revela que o problema ainda reside na falta de eficácia social das leis, fruto da resistência da sociedade civil e das autoridades competentes, não raras vezes, no cumprimento integral das disposições normativas. A resistência na aplicação escorreita da lei impede que os objetivos consagrados na Convenção de Nova lorque, como também é designada a Convenção acima citada, e, por consequência, das normas previstas no Estatuto da Pessoa com Deficiência sejam alcançados em sua plenitude. Os obstáculos à efetividade da Lei transbordam dos aspectos técnicos e resvalam na conscientização e sensibilidade de apreender que a diferença é um traço intrínseco da condição humana e que numa sociedade plural e laica é fundamental a afirmação da diferença como direito para que se promovam políticas públicas e se efetivem as garantias fundamentais a essa parcela da população. Afinal, todos são iguais perante a lei, mas nem todos são reconhecidos como iguais e tem igualdade de oportunidades no acesso aos direitos previstos nas leis.

O reconhecimento social é, portanto, a chave essencial que permite superar os desafios postos à efetividade do Estatuto da Pessoa com Deficiência. É preciso compreender no mosaico humano plural que o outro é titular de idêntica dignidade, a exigir igualitária participação no meio social, com paridade de oportunidades. Em outra oportunidade, já se destacou que é "indispensável que a sociedade reconheça as pessoas com deficiência como iguais em respeito e consideração, sujeitos 
independentes e com voz para interação com outros parceiros na sociedade, em simetria de oportunidade, para alcançar a estima social desejada e desenvolverem livremente sua personalidade de acordo com seu projeto pessoal de plena realização existencial" (BARBOZA, ALMEIDA, 2017, p. 36).

Os tribunais superiores já tiveram a oportunidade de se manifestar a respeito dos efeitos do modelo social da deficiência. O Supremo Tribunal Federal, na Ação Direta de Inconstitucionalidade n. 5357, julgou constitucionais o parágrafo primeiro do artigo 28 e caput do artigo 30 do Estatuto da Pessoa com Deficiência, que estabelecem a obrigatoriedade de as escolas privadas promoverem a inclusão de pessoas com deficiência no ensino regular e prover as medidas de adaptação necessárias sem que ônus financeiro seja repassado às mensalidades, anuidades e matrículas. Por sua vez, o Superior Tribunal de Justiça, no julgamento do Recurso Especial n. 1.733.468-MG, no qual examinou em ação de compensação por dano moral a falta de acessibilidade a transporte público municipal à pessoa com deficiência usuária de cadeira de rodas motorizada, asseverou que a CDPD alçou a "acessibilidade a princípio geral a ser observado pelos Estados Partes, atribuindo-lhe, também, o caráter de direito humano fundamental".

Como se constata, a adoção do modelo social inova substancialmente ao compreender o fenômeno da deficiência como a resultante da interação das barreiras socialmente impostas às pessoas com deficiência com os impedimentos de longa duração que apresentam, sendo essa uma das grandes conquistas promovidas pela Convenção e pelo EPD: a deficiência deixa de ser uma questão exclusivamente individual e passa a ter um componente social. Tal modelo exige, por um lado, a inclusão plena da pessoa com deficiência e, pelo outro, o dever do Poder Público e da sociedade de tornar o meio em que vivemos um lugar viável para a convivência entre todas as pessoas - com ou sem deficiência - e em condições de exercerem seus direitos, satisfazerem suas necessidades e desenvolverem suas potencialidades.

O EPD pôs fim ao regime das (in)capacidades até então existente na Lei Civil, que instaurou um sistema legal de discriminação, ao rotular a pessoa com deficiência mental ou intelectual como "louco de todo gênero" e, posteriormente, como enfermo ou deficiente mental, vedando-lhes total ou parcialmente a prática dos atos da vida civil, inclusive de natureza existencial. Através da curatela, em sua feição tradicional de substituição, se não de verdadeira ocultação, da vontade do curatelado, a pessoa e seus bens ficavam submetidos ao exclusivo poder decisório do curador, que se tornava senhor dos rumos da vida da pessoa com deficiência, especialmente no caso de deficiência mental ou intelectual. Reconstruir os novos perfis da curatela à luz do EPD e do vigente Código de Processo Civil, em plena obediência às normas da CDPD, tem sido um trabalho árduo, mas indispensável para garantir o resgate e a promoção da autonomia das pessoas com deficiência (BARBOZA, 2016; ALMEIDA, 2019).

Como se vê, o EPD impactou institutos centrais do direito civil, e continua a desafiar outros ramos do Direito a realizar trabalho meticuloso de ressignificação e/ou reconstrução de seus conceitos, sempre à luz dos imperativos de inclusão social e do indeclinável respeito aos direitos fundamentais das pessoas com deficiência.

\section{PERFIL DA INFORMAÇÃO NO CONTEXTO DA LEI BRASILEIRA DE INCLUSÃO}

Qualquer abordagem que tenha como objeto a "informação" exige uma apreciação, ainda que breve e panorâmica, do amplo campo compreendido pelo termo. Originada do Latim in mais formare - informare, indicava "modelar, dar forma", "formar", 
adquiriu a conotação de "formar uma ideia de algo", que passou depois a "descrever" e mais tarde se generalizou em "contar algo a alguém sobre alguma coisa". Ao longo do tempo a noção de informar como "contar algo" consubstanciou-se no ato de "conhecimento comunicado", na "informação", como ato ou efeito de informar, que se multiplicou em vários segmentos, que têm um papel importantíssimo na sociedade atual, inclusive sob o aspecto patrimonial, tendo algumas informações valor inestimável. O significado original, a rigor, não se perdeu e se desenvolveu fortemente na área da comunicação, que encontra na atividade jornalística forte campo para que se identifique o "comunicado" e a "formação", notadamente de opinião.

Paralelamente, após a Segunda Grande Guerra Mundial, a informação emerge como ciência - a ciência da informação - graças à tecnologia da informação e seus impactos globais, com o desenvolvimento e a disseminação do uso de redes de computadores, que caracterizam a nossa sociedade como uma sociedade da informação. Com o processo evolutivo que conferiu natureza digital ${ }^{3}$ à informação, esta torna-se condição básica para o desenvolvimento econômico juntamente com o capital, o trabalho e a matéria-prima. Por outro lado, como destacam Rafael Capurro e Birger Hjorland (2007, p. 149), o "impacto da tecnologia da informação sobre as ciências naturais e sociais em particular, tornou essa noção corriqueira um conceito altamente controvertido".

Segundo os citados autores (2007, p. 193), “[...] os pesquisadores devem ser explícitos sobre como definem este e outros termos teóricos [...]", visto que "existem muitos conceitos de informação, que se encontram inseridos em estruturas teóricas mais ou menos explícitas", sendo fácil se "perder a orientação" quando se trata de informação.

Como destaca Michael K. Buckland (1991, p. 10), qualquer objeto particular, documento, dado ou evento pode ser considerado informativo dependendo das circunstâncias. Nessa perspectiva, quando se trata de pessoa com deficiência, que mereceu tratamento próprio do legislador, a compreensão do que é informação deve ser buscada nos textos legislativos.

De início cumpre salientar que a pessoa com deficiência tem assegurado todos os direitos reconhecidos pela Constituição da República, em plena igualdade de condições com a demais pessoas. Em matéria de informação, de acordo com o inciso $\mathrm{XIV}$, do art. $5^{\circ}$, da Lei Maior, é assegurado a pessoa com deficiência o acesso à informação e resguardado o sigilo da fonte, quando necessário ao exercício profissional. Como todas as demais pessoas, tem também direito de receber dos órgãos públicos informações de seu interesse particular, ou de interesse coletivo ou geral, que serão prestadas no prazo da lei, sob pena de responsabilidade, ressalvadas aquelas cujo sigilo seja imprescindível à segurança da sociedade e do Estado, conforme inciso XXXIII 4, do citado art. $5^{\circ}$. São direitos fundamentais, integrantes do elenco do artigo $5^{\circ}$, da Lei Maior, que tutelam o "direito de informação", conceito amplo, que envolve os direitos de: informar, se informar e de ser informado. Trata-se, como esclarece o Ministro Humberto Martins (2020), de "um direito e um dever", que encontram raízes no desenvolvimento da liberdade.

\footnotetext{
3 Digital é igualmente palavra que tem diversos significados. Utiliza-se aqui no sentido utilizado pela informática, adjetivo que se refere ao que trabalha exclusivamente com valores binários.

4 Observe-se que, de acordo com o art. $4^{\circ}$, da Lei n. 12.527, de 18 de novembro de 2011, que regula o acesso a informações previsto no inciso XXXIII do art. $5^{\circ}$, considera-se, para os efeitos da citada lei, como informação: "dados, processados ou não, que podem ser utilizados para produção e transmissão de conhecimento, contidos em qualquer meio, suporte ou formato".
} 
Considerado esse último aspecto, o direito à informação aproxima-se da liberdade de informação, como liberdade de expressão, igualmente tutelada pela Constituição da República, no inciso IV, do art. $5^{\circ}$, que assegura a livre manifestação do pensamento, vedando o anonimato, e mais especificamente a plena liberdade de informação jornalística em qualquer veículo de comunicação social, nos termos do $\S 1^{\circ}$, do art. 220 .

Tais manifestações do direito à informação são asseguradas à pessoa com deficiência, mas não serão objeto de análise, por escaparem dos estreitos limites do presente trabalho, que procura apresentar o perfil da informação na normativa especial que tutela a pessoa com deficiência. A proteção conferida ao direito de acesso à informação da pessoa com deficiência tem igualmente sede constitucional, uma vez que se encontra estabelecida na CDPD, no artigo 9, dedicado à "acessibilidade". 5

De acordo com este dispositivo, os Estados Partes, a fim de possibilitar às pessoas com deficiência viver de forma independente e participar plenamente de todos os aspectos da vida, tomarão as medidas apropriadas para assegurar às pessoas com deficiência o acesso, em igualdade de oportunidades com as demais pessoas à informação e comunicação, inclusive aos sistemas e tecnologias da informação e comunicação, bem como a outros serviços e instalações abertos ao público ou de uso público, tanto na zona urbana como na rural. Tais medidas incluirão a identificação e a eliminação de obstáculos e barreiras à acessibilidade e serão aplicadas, entre outros, a informações, comunicações e outros serviços, inclusive serviços eletrônicos e serviços de emergência.

De igual modo, deverão ser promovidas: outras formas apropriadas de assistência e apoio a pessoas com deficiência, a fim de assegurar a essas pessoas o acesso a informações; o acesso de pessoas com deficiência a novos sistemas e tecnologias da informação e comunicação, inclusive à Internet; e, desde a fase inicial, a concepção, o desenvolvimento, a produção e a disseminação de sistemas e tecnologias de informação e comunicação, a fim de que esses sistemas e tecnologias se tornem acessíveis a custo mínimo.

Delineia-se, desse modo, a natureza do direito de acesso à informação no contexto da acessibilidade, que foi definida pela Lei Brasileira de Inclusão-Estatuto da Pessoa com Deficiência (Lei 13.146/2015), para fins de sua aplicação, como: a possibilidade e condição de alcance para utilização, com segurança e autonomia, de espaços, mobiliários, equipamentos urbanos, edificações, transportes, informação e comunicação, inclusive seus sistemas e tecnologias, bem como de outros serviços e instalações abertos ao público, de uso público ou privados de uso coletivo, tanto na zona urbana como na rural, por pessoa com deficiência ou com mobilidade reduzida.

Observe-se que qualquer entrave, obstáculo, atitude ou comportamento que limite ou impeça a participação social da pessoa, bem como o gozo, a fruição e o exercício de seus direitos à acessibilidade, à liberdade de movimento e de expressão, à comunicação, ao acesso à informação, constitui uma barreira, como definida no inciso IV, do mencionado art. $3^{\circ}$, do Estatuto de Pessoa com Deficiência (EPD). As barreiras nas comunicações e na informação são especificadas como: qualquer entrave, obstáculo, atitude ou comportamento que dificulte ou impossibilite a expressão ou o

5 Cuidou a CDPD, no artigo 21, também da Liberdade de expressão e de opinião e acesso à informação, devendo os Estados Partes tomar todas as medidas apropriadas para assegurar que as pessoas com deficiência possam exercer seu direito à liberdade de expressão e opinião, inclusive à liberdade de buscar, receber e compartilhar informações e ideias, em igualdade de oportunidades com as demais pessoas e por intermédio de todas as formas de comunicação de sua escolha, conforme o disposto no Artigo 2 da Convenção. Como acima observado, o tema não está contido no objeto do presente trabalho. 
recebimento de mensagens e de informações por intermédio de sistemas de comunicação e de tecnologia da informação.

As pessoas com deficiência têm assegurado o direito a receber atendimento prioritário, sobretudo com a finalidade de acesso a informações e disponibilização de recursos de comunicação acessíveis, sendo esse direito extensivo ao acompanhante da pessoa com deficiência ou ao seu atendente pessoal (EPD, art. $9^{\circ}$, V, e $\S 1^{\circ}$ ).

O EPD, ao tratar da Acessibilidade, dedicou um Capítulo ao Acesso à Informação e à Comunicação (art. 63 a 73), o qual assume grande importância na contemporaneidade, momento em que o mundo se tornou "digital”, isto é, em que a comunicação se opera maciçamente por meio dos recursos fornecidos pela tecnologia digital através da internet. Merece destaque o art. 63, que torna obrigatória a acessibilidade nos sítios da internet mantidos por empresas com sede ou representação comercial no País ou por órgãos de governo, para uso da pessoa com deficiência, garantindo-lhe acesso às informações disponíveis, conforme as melhores práticas e diretrizes de acessibilidade adotadas internacionalmente. Os sítios devem conter símbolo de acessibilidade em destaque e os telecentros comunitários que receberem recursos públicos federais para seu custeio ou sua instalação e lan houses devem possuir equipamentos e instalações acessíveis, conforme $\S \S 1^{\circ}$ e $2^{\circ}$, do referido artigo.

Nessa linha, cuidou também o EPD da Tecnologia Assistiva ou ajuda técnica, definida, para fins de aplicação do EPD, no art. $3^{\circ}$, inciso $\mathrm{V}$, como: produtos, equipamentos, dispositivos, recursos, metodologias, estratégias, práticas e serviços que objetivem promover a funcionalidade, relacionada à atividade e à participação da pessoa com deficiência ou com mobilidade reduzida, visando à sua autonomia, independência, qualidade de vida e inclusão social.

Embora o artigo 53, do EPD, afirme ser a acessibilidade o direito que garante à pessoa com deficiência ou com mobilidade reduzida viver de forma independente e exercer seus direitos de cidadania e de participação social, constata-se ser a tecnologia assistiva, como acima definida, o instrumento fundamental e indispensável não apenas para a efetivação desse direito, mas principalmente para que se cumpra o objetivo maior do EPD: a inclusão social.

Por outro lado, quando se considera o modelo social de deficiência, que se traduz no conceito estampado na CDPD (artigo 1), segundo o qual resta claro ser a deficiência a resultante da interação de um impedimento pessoal com uma barreira social, a informação, em suas diversas vertentes, emerge como meio de acesso essencial para que alcance o propósito da CDPD de promover, proteger e assegurar o exercício pleno e equitativo de todos os direitos humanos e liberdades fundamentais por todas as pessoas com deficiência e promover o respeito pela sua dignidade inerente.

A importância e natureza própria que a informação assume no contexto da deficiência são indiscutíveis, visto que constitui elemento essencial da acessibilidade que, conforme entendimento do STF, acima citado, foi elevado à categoria de "princípio geral a ser observado pelos Estados Partes, atribuindo-Ihe, também, o caráter de direito humano fundamental".

\section{NOTAS CONCLUSIVAS: OS DESAFIOS POSTOS PELA COVID-19 À INFORMAÇÃO DAS PESSOAS COM DEFICIÊNCIA}

No momento em que a pandemia da Covid-19 assola o mundo, torna-se imperioso dispensar atenção especial às pessoas com deficiência e aos direitos que lhes são 
especialmente assegurados no que concerne à informação relativa à saúde. Dentre esses direitos, cabe destacar o direito de acesso às informações prestadas e recebidas, por meio de recursos de tecnologia assistiva e de todas as formas de comunicação previstas no inciso $V$ do art. $3^{\circ}$ do EPD, prestadas pelos serviços de saúde públicos e privados (art. 24, do EPD).

De acordo com a OMS, é "preciso tomar medidas para garantir que as pessoas com deficiência tenham acesso aos serviços de saúde, água e saneamento e às informações de saúde pública de que necessitam". A questão foi objeto de considerações específicas da OMS, ao incluir entre as populações que podem ser mais afetadas pela Covid-19, as pessoas com deficiência, observando, porém, que medidas de proteção apropriadas podem mitigar esse impacto. A OMS apresentou as razões pelas quais as pessoas com deficiência tem um maior risco de contrair a Covid-19, mencionando: obstáculos à implementação de medidas básicas de higiene, tais como a lavagem das mãos (por exemplo, as pias, lavatórios ou bombas d'água podem ser fisicamente inacessíveis, ou a pessoa pode ter uma dificuldade física em esfregar as mãos adequadamente); necessidade de encostar nos objetos para obter informações sobre o ambiente ou para se apoiar fisicamente; dificuldades no acesso a informações de saúde pública (WHO, 2020, passim).

As informações relativas às pessoas com deficiência e/ou seus cuidadores são variadas e compreendem: (i) as que ela própria deve prestar, como a indicação de pessoas de confiança, familiares ou não, que devem ser informadas caso venha a precisar de atendimento domiciliar ou hospitalar, medicamentos, plano de saúde; (ii) as que lhe devem ser prestadas por outras pessoas, como as que lhes dão assistência, como orientações sobre quando e como chamar profissionais da saúde, números de telefone de contato, e as que trabalham nos serviços púbicos de saúde; e, (iii) as que ela solicita, como as que se referem ao seu estado de saúde, possibilidade de tratamento e cura. É necessário que lhes seja assegurada a acessibilidade dos canais de comunicação e das informações de saúde pública, com observância do que determina o EPD.

Como amplamente destacado em todos os meios de comunicação, para o enfrentamento da pandemia é primordial que as informações a respeito da prevenção e controle do coronavírus sejam acessíveis a todas as pessoas, por todos os meios possíveis. Vale dizer: é preciso que não haja barreiras na comunicação escrita, na comunicação virtual e na comunicação interpessoal em todos os ambientes sociais (SASSAKI, 2009, p. 10-16). Talvez em nenhum outro tempo a eliminação de barreiras de comunicação se fez tão necessária.

Nesse cenário, as informações digitais, notadamente as obtidas pela internet, se tornam de suma importância. Contudo, as barreiras digitais existentes impedem o acesso das pessoas com deficiência, sendo mínimo o número das que tem acesso à web. No Brasil somente $0,7 \%$, das 14 milhões de páginas na internet, tem acessibilidade para pessoas com deficiência (VENTURA, 2020).

A falta de acessibilidade às informações, infelizmente, se encontra no cenário mundial. Segundo relatório da Organização das Nações Unidas (2020), "a pandemia está intensificando essas desigualdades - e produzindo novas ameaças para as pessoas com deficiência, que enfrentam a falta de informações acessíveis sobre saúde pública e barreiras significativas para implementar medidas básicas de higiene, assim como falta de acesso a instalações de saúde". O acesso à informação se torna, desse modo, vital, visto que se as pessoas com deficiência contraem Covid-19, aumenta a probabilidade de agravarem suas condições de saúde, o que pode acarretar sua morte. 
No Brasil, o direito fundamental de acesso à informação está assegurado às pessoas com deficiência, pela Constituição da República e pelo EPD. Impõe-se, mais do que nunca, dar efetividade a tais normas como forma de concretização da acessibilidade e da inclusão social.

\section{REFERÊNCIAS}

ALMEIDA, Vitor. A capacidade civil das pessoas com deficiência e os perfis da curatela. Belo Horizonte: Fórum, 2019.

BACHILO, Illaria L. Sobre os termos e definições no direito da informação. Revista de Investigações Constitucionais, Curitiba, v. 2, n. 3, p. 207-222, set./dez. 2015.

BARBOZA, Heloisa Helena. Curatela em nova perspectiva. In: SÁ, Maria de Fátima Freire de; NOGUEIRA, Roberto Henrique Pôrto; SCHETTINI, Beatriz. (orgs.). Novos Direitos Privados. Belo Horizonte: Arraes Editores Ltda, 2016.

BARBOZA, Heloisa Helena; ALMEIDA, Vitor. Reconhecimento e inclusão social das pessoas com deficiência. Revista Brasileira de Direito Civil, Belo Horizonte, v. 13, p. 1737, jul./set. 2017.

BINENBOJM, Gustavo. Liberdade igual: o que é e porque importa. Rio de Janeiro: História Real, 2020.

CAPURRO, Rafael; HJORLAND, Birger. O conceito de informação. Perspectivas em ciência da informação, Belo Horizonte, v. 12, n. 1, p. 148-207, abr. 2007. Disponível em: http://www.scielo.br/scielo.php?script=sci_arttext\&pid=S1413-

99362007000100012\&lng=en\&nrm=iso. Acesso em: 28 ago. 2020.

INTERNATIONAL DISABILITY ALLIANCE. Toward a disability-inclusive COVID19 response: 10 recommendations from the International Disability Alliance, 2020.

Disponível em:

https://www.internationaldisabilityalliance.org/sites/default/files/ida_recommendatio ns_for_disability-inclusive_covid19_response_final.pdf. Acesso em: 13 ago. 2020.

MARTINS, Humberto. $O$ dever de informar e o direito à informação ( $I$ - a perspectiva do Direito do Consumidor). Consultor Jurídico, 19 fev. 2020. Disponível em: https://www.conjur.com.br/2020-fev-19/dever-informar-direito-informacao-parte. Acesso em: 15 ago. 2020.

ORGANIZAÇÃO DAS NAÇÕES UNIDAS. Policy brief: a disability-inclusive response to COVID-19, maio 2020. Disponível em: https://unsdg.un.org/sites/default/files/202005/Policy-Brief-A-Disability-Inclusive-Response-to-COVID-19.pdf. Acesso em: 28 ago.2020.

ORGANIZAÇÃO MUNDIAL DA SAÚDE. Disability considerations during the COVID-19 outbreak. 2020. Disponível em: https://www.who.int/publications/i/item/WHO-2019nCoV-Disability-2020-1. Acesso em: 28 ago. 2020.

ORGANIZAÇÃO PAN-AMERICANA DE SAÚDE. Considerações sobre pessoas com deficiência durante o surto de COVID-19. 2020. Disponível em: 
https://iris.paho.org/bitstream/handle/10665.2/52063/OPASBRACOVID1920017_por.pd f?sequence=7\&isAllowed=y. Acesso em 12 ago. 2020.

SABLE-SMITH, Bram. People with disabilities find the coronavirus has cut them off from their caregivers. Disponível em: https://www.npr.org/sections/healthshots/2020/06/16/875944357/people-with-disabilities-find-the-coronavirus-has-cutthem-off-from-their-

caregi?utm_campaign=storyshare\&utm_source=twitter.com\&utm_medium=social. Acesso em: 12 ago. 2020.

SANTOS, Boaventura de Souza. A cruel pedagogia do vírus. Coimbra: Almedina, 2020. Disponível em: file:///C:/Users/55219/Downloads/Livro\%20Boaventura\%20\%20A\%20pedagogia\%20do\%20\%20virus.pdf.pdf. Acesso em 05 maio 2020.

SARLET, Ingo Wolfgang; MOLINARO, Carlos Alberto. Direito à informação e direito de acesso à informação como direitos fundamentais na Constituição brasileira. Revista da AGU, Brasília-DF, ano XIII, n. 42, p. 09-38, out./dez. 2014.

SASSAKI, Romeu Kazumi. Inclusão: acessibilidade no lazer, trabalho e educação. Revista Nacional de Reabilitação (Reação), São Paulo, ano XII, mar./abr. 2009.

VENTURA, Luiz A. S. Coronavírus: isolamento reforça importância da acessibilidade digital. Blog Vencer Limites, Estadão, 20 mar. 2020. Disponível em: https://brasil.estadao.com.br/blogs/vencer-limites/coronavirus-isolamento-reforcaimportancia-da-acessibilidade-digital/?fbclid=IwAR2W-

SVgkbuQBL_kK2xvXBmVLpsWoUQVkr8nScHnb4dXZN5gVyj2KXu8qnM. Acesso em: 15 ago. 2020. 